and Department of Medicine, University of Cape Town (UCT), Cape Town, South Africa. ${ }^{4}$ Dept of Medicine, Imperial College London, London, UK. ${ }^{5}$ Division of Medical Microbiology, and Institute of Infectious Disease and Molecular Medicine, UCT, Cape Town, South Africa.

Correspondence: Jennifer Hughes, MSF, Town I properties, Sulani Drive, Khayelitsha, PO Box 27401, Rhine Rd, Sea Point, Cape Town, South Africa. E-mail: msfocb-khayelitsha-tbdoc@brussels.msf.org

Received: Aug 182015 | Accepted: Oct 242015

Conflict of interest: None declared.

\title{
References
}

1 World Health Organization. Companion Handbook to the WHO Guidelines for Programmatic Management of Drug Resistant Tuberculosis. WHO/HTM/TB/2014.11. Geneva, WHO, 2014

2 Cox HS, Furin J, Mitnick CD, et al. The need to accelerate access to new drugs for multidrug-resistant tuberculosis. Bull World Health Organ 2015; 93: 491-497.

3 Isaakidis P, Cox HS, Varghese B, et al. Ambulatory multi-drug resistant tuberculosis treatment outcomes in a cohort of HIV-infected patients in a slum setting in Mumbai, India. PLoS One 2011; 6: e28066.

4 Cox HS, Hughes JA, Daniels J, et al. Community-based treatment of drug-resistant tuberculosis in Khayelitsha, South Africa. Int J Tuberc Lung Dis 2014; 18: 441-448.

5 Dheda K, Shean K, Zumla A, et al. Early treatment outcomes and HIV status of patients with extensively drug-resistant tuberculosis in South Africa: a retrospective cohort study. Lancet 2010; 375: 1798-1807.

6 Cegielski JP, Dalton T, Yagui M, et al. Extensive drug resistance acquired during treatment of multidrug-resistant tuberculosis. Clin Infect Dis 2014; 59: 1049.

7 Pietersen E, Ignatius E, Streicher E, et al. Long-term outcomes of patients with extensively drug-resistant tuberculosis in South Africa: a cohort study. The Lancet 2014; 383: 1230-1239.

8 Zhang L, Pang Y, Yu X, et al. Linezolid in the treatment of extensively drug-resistant tuberculosis. Infection 2014; 42: 705-711.

9 Lee M, Cho SN, Barry CE III, et al. Linezolid for XDR-TB - final study outcomes. N Engl J Med 2015; 373 : 290-291.

10 Hillemann D, Rusch-Gerdes S, Richter E. In vitro-selected linezolid-resistant Mycobacterium tuberculosis mutants. Antimicrob Agents Chemother 2008; 52: 800-801.

11 Robijns K, Harteveld AR, Greijdanus B, et al. An interlaboratory quality control programme for the measurement of tuberculosis drugs. Eur Respir J 2015; 46: 268-271.

12 Daskapan A, de Lange WC, Akkerman OW, et al. The role of therapeutic drug monitoring in individualised drug dosage and exposure measurement in tuberculosis and HIV co-infection. Eur Respir J 2015; 45: 569-571.

\section{Mediastinoscopy after negative endoscopic mediastinal nodal staging: can it be omitted?}

To the Editor:

We read with great interest the study by VILMANN et al. [1], proposing new guidelines for diagnosis and staging of lung cancer, particularly discussing the role of combined endobronchial ultrasound (EBUS) and endoscopic oesophageal ultrasound (EUS) in mediastinal nodal staging. We have several comments on this paper.

Various other guidelines have recently already been published on this matter, from the American College of Chest Physicians (ACCP) in 2013 [2] and the European Society of Thoracic Surgeons (ESTS) in 2014 [3]. When comparing these three guidelines, specifically on invasive mediastinal nodal staging, notable differences are few. However, it is interesting to see the fluctuating role of mediastinoscopy after negative endoscopic staging through EBUS and/or EUS. The ESTS guidelines have stated that mediastinoscopy is indicated after negative endoscopic staging. Then again, mediastinoscopy has a much more optional character in the ACCP guidelines [2], emphasising the thoroughness with which the procedure is performed rather than which test is used. It would seem that, the fewer surgeons are involved in the development of the guideline, the more non-committal mediastinoscopy becomes in the diagnostic algorithm of the mediastinum. In the new guidelines by VILMANn et al. [1], a combined effort between surgeons, respiratory physicians and endoscopists, mediastinoscopy after negative endoscopic staging is 
recommended when imaging studies demonstrate abnormal mediastinal/hilar nodes, and can be considered when imaging studies show no mediastinal involvement. Only for mediastinal nodal restaging, mediastinoscopy is said to be indicated after negative endoscopic staging [1].

All can agree that the combination of endoscopic and surgical techniques results in the highest accuracy of mediastinal nodal staging [3]. Therefore, we are surprised to notice this trend of omitting mediastinoscopy in the recent guidelines $[1,2]$ in favour of performing endoscopic staging alone. Is mediastinoscopy such a feared procedure that should be avoided at all costs? Vilmann et al. [1] stated that mediastinoscopy is associated with morbidity and significant costs. However, in a contemporary series with 1970 patients undergoing mediastinoscopy [4], mortality and recurrent laryngeal nerve injury was $0 \%$, and bleeding complications requiring sternotomy $0.1 \%$. Additionally, most procedures can be performed in an outpatient setting in $20 \mathrm{~min}$, sampling three nodal stations medianly. These numbers underscore the safety of the procedure, rivalling data from endoscopic techniques.

However, the surgical community also acknowledges the value of endoscopic staging of the mediastinum, certainly as the first-line invasive diagnostic tool. Moreover, EUS has the ability to access station 8 and 9 [1], unreachable by mediastinoscopy and EBUS. Even the surgical guidelines by the ESTS consider the omission of mediastinoscopy after a negative EBUS/EUS, but only if the number of nodes explored and the number of needle passes in each node meet the established requirements [3]. In this regard, we find it appropriate that VILMANN et al. [1] have stated that "complete mediastinal staging" by endoscopic techniques should include the sampling of at least three mediastinal nodal stations, similar to the requirements set by the ESTS [3]. As shown in a recent multicentre study, false-negative results after EBUS was $2.4 \%$ when sampling of at least three mediastinal stations were performed, but rose to $15 \%$ when two or fewer were sampled [5]. However, VILMANn et al. [1] do not offer further quality definitions or recommendations regarding specimen acquisition and handling techniques [6] like a minimal number of aspirations per target lymph node station, or the use of rapid on-site cytology evaluation. Furthermore, learning curves of individual practitioners show substantial variability, affecting diagnostic yield [1]. With varying operator experiences and differing clinical practices, the wide range of FN results reported after endoscopic staging is not unexpected. Reported FN rates range from $2-15 \%$ for EBUS, $1-20 \%$ for EUS and $0-13 \%$ for EBUS/EUS combined [7]. We expect the real-world practice to be even more variable. Then again, completeness of mediastinoscopy in daily practice may be similarly inconsistent, meeting guideline standards in only $40 \%$ [8]. Therefore, we would like to emphasise the need for continued outcomes-based measures of quality, individually and institutionally, reviewing the negative predictive value and diagnostic accuracy of EBUS/EUS procedures and preoperative mediastinal nodal staging in general on a regularly basis. In our own institution, we found 8.8 mediastinoscopies have to be performed to prevent one futile thoracotomy after negative endoscopic staging [9], a number which is lowered to 6.1 when patients have suspicious mediastinal lymph nodes on fluorodeoxyglucose-positron emission tomography. Specifically for cN1-patients, 10 mediastinoscopies are needed to detect one false-negative $\mathrm{N} 2$ on endosonography [10]. As such, in our centre, all patients will undergo mediastinoscopy after negative endoscopic staging.

The question remains whether endoscopic techniques like EBUS and EUS are meant to substitute the place of mediastinoscopy in the algorithm for mediastinal staging in lung cancer patients, or whether these techniques are complementary to each other. We believe firmly in the last.

@ERSpublications Mediastinoscopy should not be omitted after negative EBUS/EUS http://ow.ly/T4Qap

Wilson W.L. Li ${ }^{1}$, Erik F.M. van der Heijden ${ }^{2}$ and Ad F.T.M. Verhagen ${ }^{1}$

${ }^{1}$ Dept of Cardiothoracic Surgery, Radboud University Medical Centre, Nijmegen, The Netherlands. ${ }^{2}$ Dept of Pulmonary Diseases, Radboud University Medical Centre, Nijmegen, The Netherlands.

Correspondence: Wilson W.L. Li, Dept of Cardiothoracic Surgery, Radboud University Medical Centre, P.O. Box 9101, 6500 HB Nijmegen, The Netherlands. E-mail: wilson.li@radboudumc.nl

Received: July 192015 | Accepted: July 212015

Conflict of interest: Disclosures can be found alongside the online version of this article at erj.ersjournals.com

\section{References}

1 Vilmann P, Clementsen PF, Colella S, et al. Combined endobronchial and oesophageal endosonography for the diagnosis and staging of lung cancer. Eur Respir J 2015; 46: 40-60.

2 Silvestri GA, Gonzalez AV, Jantz MA, et al. Methods for staging non-small cell lung cancer: Diagnosis and management of lung cancer, 3rd ed: American College of Chest Physicians evidence-based clinical practice guidelines. Chest 2013; 143: e211S-e250S.

3 De Leyn P, Dooms C, Kuzdzal J, et al. Revised ESTS guidelines for preoperative mediastinal lymph node staging for non-small-cell lung cancer. Eur J Cardiothorac Surg 2014; 45: 787-798. 
4 Wei B, Bryant AS, Minnich DJ, et al. The safety and efficacy of mediastinoscopy when performed by general thoracic surgeons. Ann Thorac Surg 2014; 97: 1878-1883.

5 Sanz-Santos J, Serra M, Gallego M, et al. Determinants of false-negative results in non-small-cell lung cancer staging by endobronchial ultrasound-guided needle aspiration. Eur J Cardiothorac Surg 2015; 47: 642-647.

6 van der Heijden EH, Casal RF, Trisolini R, et al. Guideline for the acquisition and preparation of conventional and endobronchial ultrasound-guided transbronchial needle aspiration specimens for the diagnosis and molecular testing of patients with known or suspected lung cancer. Respiration 2014; 88: 500-517.

7 Zhang R, Ying K, Shi L, et al. Combined endobronchial and endoscopic ultrasound-guided fine needle aspiration for mediastinal lymph node staging of lung cancer: a meta-analysis. Eur J Cancer 2013; 49: 1860-1867.

8 Smulders SA, Smeenk FW, Janssen-Heijnen ML, et al. Surgical mediastinal staging in daily practice. Lung Cancer 2005; 47: 243-251.

9 Verhagen AF, Schuurbiers OC, Looijen-Salamon MG, et al. Mediastinal staging in daily practice: endosonography, followed by cervical mediastinoscopy. Do we really need both? Interact Cardiovasc Thorac Surg 2013; 17: 823-828.

10 Dooms C, Tournoy KG, Schuurbiers O, et al. Endosonography for mediastinal nodal staging of clinical N1 non-small cell lung cancer: a prospective multicenter study. Chest 2015; 147: 209-215.

Eur Respir J 2015; 46: 1846-1848 | DOI: 10.1183/13993003.01166-2015 | Copyright (CERS 2015

From the authors:

We read with interest the comments of $\mathrm{Li}$ and colleagues on the need for a routine mediastinoscopy following a nodal negative endosonographic mediastinal evaluation. This topic is frequently a subject of discussion in multidisciplinary lung cancer teams and therefore deserves full attention.

Accurate mediastinal nodal staging is required to provide patients with the optimal treatment. Roughly speaking, about half the patients that are referred for an endosonographic mediastinal evaluation have metastatic nodal involvement. Both endobronchial ultrasound (EBUS) and endoscopic oesophageal ultrasound (EUS) are excellent techniques in confirming metastases, but have limitations in excluding them. Routine performance of mediastinoscopy in all patients that are staged negative by EBUS/EUS confirms endosonography findings in the vast majority of cases. In both the study by VeRHAGEN et al. [1] and the ASTER study [2], mediastinoscopy did not provide any benefit in eight out of nine patients. The drawbacks for these patients are obvious: a delay in the diagnostic workup and start of treatment, performance of unnecessary surgery and anaesthesia, and use of scarce healthcare recourses.

For the optimal use of subsequent surgical staging, the key question is to identify predictors for false negative EBUS/EUS outcomes. They could be related to specific imaging findings (nodal size, 2-fluoro-2-deoxy-D-glucose positron emission tomography uptake or specific sonographic characteristics) and tumour histology. Another approach is to assess the thoroughness of the endosonographic evaluation: performance of EBUS alone versus the EBUS-EUS combination, systematic nodal evaluation of the mediastinum versus the "hit and run" approach, the number of nodal stations sampled and adequacy of nodal tissue obtained. Currently, more data are urgently needed to shed light on this issue in order to create a predictive model for false negative EBUS/EUS findings [4].

The European Society of Gastrointestinal Endoscopy/European Respiratory Society/European Society of Thoracic Surgeons guideline on combined EBUS-EUS lung cancer staging [3] provides room for the local tumour board to proceed directly to thoracoscopy (video-assisted thoracic surgery) or thoracotomy following a tumour negative endosonography, and omit a confirmatory mediastinoscopy. This is only allowed after careful consideration and in combination with meticulous monitoring and evaluation of endosonography outcomes. On this point we fully agree with $\mathrm{Li}$ and colleagues.

It should be clear that in the opinion of the guideline authors, endosonographic needle-based techniques are complementary to surgical staging and are not completely substituting it. However, mediastinoscopy should preferably be performed only in those patients with a high risk of false negative EBUS/EUS results as routine performance results in too many unnecessary surgical staging procedures. Identification of predictors of false negative EBUS/EUS outcomes is therefore important, and this is exactly the research topic on which both pulmonologists and surgeons should focus.

@ERSpublications

NSCLC staging: mediastinoscopy can be omitted in selected cases following a nodal negative EBUS/EUS examination http://ow.ly/TKKkf

Jouke T. Annema ${ }^{1}$, Paul De Leyn ${ }^{2}$, Paul Clementsen ${ }^{3}$, Mette Siemsen $^{4}$ and Peter Vilmann ${ }^{5}$

${ }^{1}$ Academic Medical Center Amsterdam, Dept of Respiratory Medicine, Amsterdam, The Netherlands. ${ }^{2}$ Thoracic Surgery, University Hospital Gasthuisberg, Leuven, Belgium. ${ }^{3}$ Dept of Pulmonology, Gentofte Hospital, University of Copenhagen, Copenhagen, Denmark. ${ }^{4}$ Thoracic Surgery, Copenhagen, Denmark. ${ }^{5}$ Hospital Herlev, Copenhagen University, Copenhagen, Denmark. 